\title{
Larval development of Dicrocoelium dendriticum in Cernuella (Xeromagna) cespitum arigonis under controlled laboratory conditions
}

\author{
C. González-Lanza, M.Y. Manga-González, R. Campo and \\ M.P. Del-Pozo \\ Departamento de Sistemas de Producción y Sanidad Animal, Estación \\ Agrícola Experimental, Consejo Superior de Investigaciones \\ Científicas (CSIC), Aptdo 788, 24080 León, Spain
}

\begin{abstract}
The larval development of Dicrocoelium dendriticum (Digenea: Dicrocoeliidae) in experimentally infected Cernuella (Xeromagna) cespitum arigonis (Schmidt, 1853), a species of mollusc important in the epidemiology of dicrocoeliosis in Spain, has been studied. A total of 948 specimens of this mollusc, distributed in five batches, were tested with individual doses of 50 to 150 parasite eggs, obtained from sheep, after 4 days without food. After infection these molluscs and control specimens were kept in an enviromental simulation chamber at $20^{\circ} \mathrm{C}, 50 \%$ relative humidity and $7 \mathrm{~h}$ of light per day. To detect the parasite, a minimum of six molluscs were examined every 20 days from day 1 postinfection (p.i.). The eggs of $D$. dendriticum were eliminated in the molluscan faeces $48 \mathrm{~h}$ post infection. The percentages of molluscs harbouring the parasite ranged between $17.53 \%$ and $75 \%$. Daughter sporocysts with undifferentiated germinal masses and occupying very reduced areas of the hepatopancreas were observed 50 days p.i. and in the period immediately following. After 110 days p.i. sporocysts with cercariae at different stages of development were found although slimeball emission was never observed.
\end{abstract}

\section{Introduction}

Dicrocoeliosis, caused by Dicrocoelium dendriticum (Rudolphi, 1819) Looss, 1899 (Digenea: Dicrocoeliidae), is an important parasitic disease from an economic and health viewpoint (Lukin, 1980; Wolff et al., 1984; Campo, 1996). It affects numerous mammal species, mainly ruminants, in several countries in Europe, Asia, America and North Africa (Malek, 1980). This parasite uses different species of land molluscs and ants, which act as first and second intermediate hosts respectively (Rosicky \& Groschaft, 1982), to complete its complex life cycle.

Mattes (1936) followed the larval development of $D$. dendriticum in experimentally infected molluscs for the first time using the species Helicella ericetorum $(=H$. itala), $H$. candidula and Zebrina detrita. Neuhaus (1936) was the first to observe migration of mature cercariae to the respiratory chamber of the snail ( $Z$. detrita), their inclusion in slimeballs and shedding by $Z$. detrita. Later Krull \& Mapes $(1952,1953)$ discovered that the second intermediate host was an ant (Formica fusca) and managed to complete the biological cycle of the parasite for the first time.

Dicrocoelium dendriticum is a very common species in ruminants in the Iberian peninsula (Cordero-delCampillo et al., 1994). Because of this, we have been studying it and its intermediate and definitive hosts for many years (Manga-González, 1983, 1987, 1992; MangaGonzález et al., 1991a,b; González-Lanza et al., 1993; Cabanas, 1995; Campo, 1996). During this research we have been able to confirm that Cernuella (Xeromagna) cespitum arigonis (Schmidt, 1853) (Mollusca, Stylommatophora) is an important species in the epidemiology of 
dicrocoeliosis in Spain. Due to this, and in order to add to our understanding of the results obtained in epidemiological studies, we considered it advisable to follow the development of $D$. dendriticum in specimens of this mollusc species, infected and kept under controlled laboratory conditions.

\section{Materials and methods}

The molluscs used for experimental infection were collected in the field from areas not frequented by cattle, preferably in the morning. The lack of $D$. dendriticum infection was confirmed by a helminthological study of $10 \%$ of the specimens collected during each sampling.

After 4 days without food, 948 specimens of C. (X.) cespitum arigonis (fig. 1), divided into five batches, were tested with different doses of $D$. dendriticum eggs collected from sheep (table 1).

To carry out the infection, molluscs were kept on a small portion of filter paper in individual Petri dishes, on which the corresponding egg dose (table 1) had been placed, for 2 days. At the end of this time, infected molluscs and controls for each batch were kept in plastic boxes in an environmental simulation chamber at $20^{\circ} \mathrm{C}$ $50 \%$ relative humidity and $7 \mathrm{~h}$ daylight per day, and fed on lettuce 'ad libitum'. In the case of batch A, the faeces of each mollusc were individually collected on each of the first 5 days of the experiment, i.e. the 2 days when the molluscs were in contact with the material contaminated with parasite eggs and the 3 days following its removal. In the case of batches $B, C$ and $E$ all faeces eliminated by each mollusc were collected once at the end of the 4th day, when the elimination of hatched eggs ceased as indicated by the results obtained in batch $A$.

All faeces eliminated by the molluscs in batches A, B, $C$ and $E$ were individually examined under the microscope to count the number of hatched and unhatched $D$. dendriticum eggs. However, faeces from batch D molluscs were processed using the sedimentation and McMaster technique, in an attempt to shorten the procedure but the results are not included as the technique proved to be unsuitable.

In order to detect the parasite in the molluscs and to follow its larval development, a minimum of six molluscs were killed and dissected every 20 days. The intensity of infection was estimated on the basis of the greater or smaller extent to which the hepatopancreas was invaded by sporocysts of $D$. dendriticum. The following categories

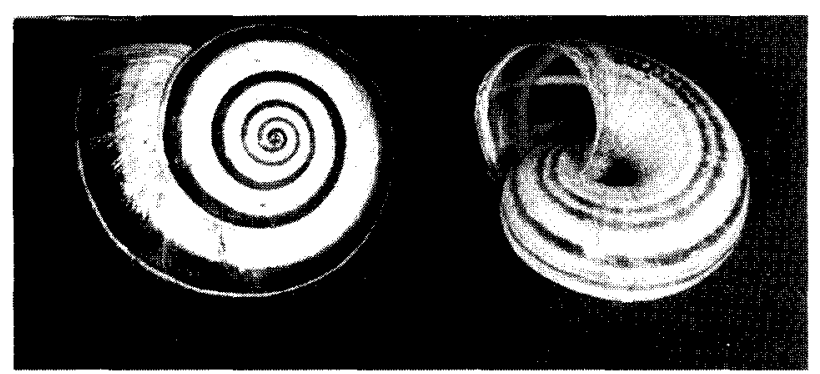

Fig. 1. Cernuella (Xeromagna) cespitum arigonis specimens, first intermediate host for Dicrocoelium dendriticum. Scale bar $=5 \mathrm{~mm}$.
Table 1. Some characteristics of infection of molluscs with Dicrocoelium dendriticum eggs from sheep.

\begin{tabular}{lccccl}
\hline & Molluscs & & & \multicolumn{2}{c}{ Eggs of D. Dendriticum } \\
\cline { 5 - 6 } Batches & Tested & Control & & $\begin{array}{c}\text { Dose/ } \\
\text { mollusc }\end{array}$ & Origin \\
\hline A & 20 & 20 & 150 & Faeces \\
B & 200 & 50 & 130 & Faeces \\
C & 300 & 75 & & 50 & Faeces \\
D & 100 & 50 & 75 & Gall bladder \\
E & 328 & 75 & 50 & Gall bladder \\
\hline
\end{tabular}

were established: (i) when only specific points of the hepatopancreas were invaded by sporocysts; (ii) when the sporocysts had already colonized part of the hepatopancreas in a migration phase, but some parasite-free areas could still be seen; and (iii) when the sporocysts had invaded all the hepatopancreas (and occasionally the genital apparatus).

The developmental stage of the sporocyst itself was studied for each of the infected molluscs in vivo and in this way three categories were established: (i) sporocysts with an undifferentiated germinal mass; (ii) sporocysts with a germinal mass containing an outline of cercariae or immature cercariae; and (iii) sporocysts with developed cercariae.

The chi-square $\left(\chi^{2}\right)$ test was used to detect any statistically significant differences between the different batches of molluscs tested, in the following categories: (i) with hatched eggs in the faeces; and (ii) with larval stages visible under the stereomicroscope. When these differences were significant, the $2 \times 2$ contingency tables were applied to compare the molluscan batches studied.

\section{Results}

According to individual analyses of the faeces of the $C$. (X.) cespitum arigonis specimens used in batch A,

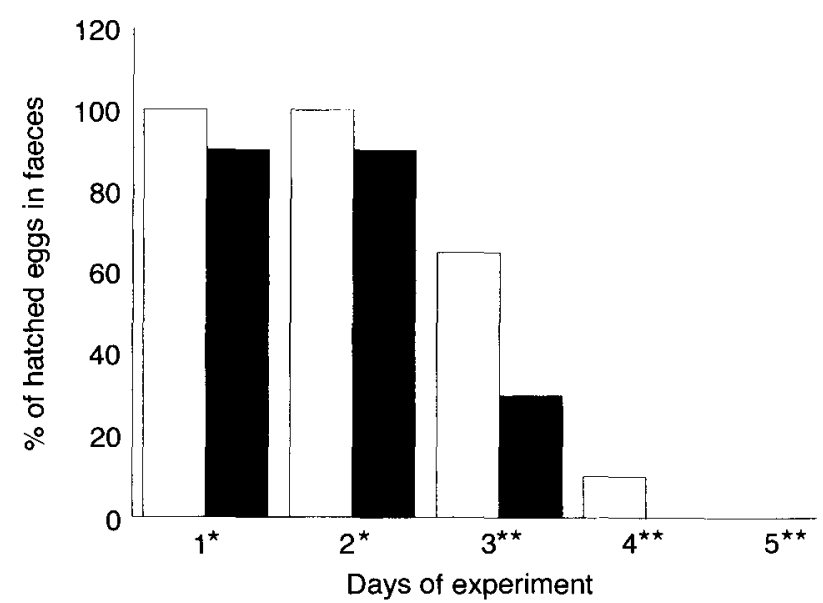

Fig. 2. Percentage of molluscs from batch A with Dicrocoelium dendriticum hatched eggs $(\square)$ and unhatched eggs ( $(\mathbf{})$ in the faeces during the first 5 days of the experiment. ${ }^{*}$ In contact with eggs; ** without infected material. 


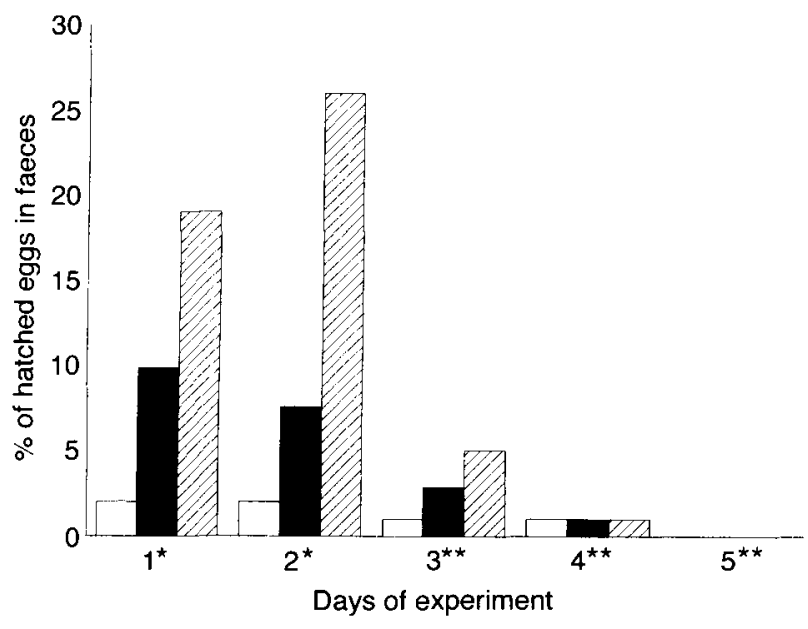

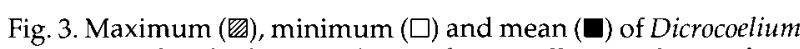
dendriticum hatched eggs observed in molluscan faeces from batch A during the first 5 days of the experiment. * In contact with eggs; ${ }^{* *}$ without infected material.

parasite eggs were not produced after the 4 th day of infection (fig. 2). The percentage of molluscs with hatched eggs in the faeces was always greater than in those eliminating unhatched eggs. Moreover, a gradual reduction in the mean number of hatched eggs per mollusc was observed (fig. 3) from the first day, when the molluscs were kept in contact with infective material $(\bar{x}=9.81 \pm$ 1.16) until the 4 th day $(\bar{x}=1)$, which is the second day after the infection is finished.

The highest percentage of molluscs with hatched eggs in the faeces was shown by batch A, also infected with the highest dose of 150 eggs/mollusc (fig. 4). On the other hand, the percentage of hatched eggs per mollusc calculated on the total found in the faeces was: $65.42 \%$ for batch A (dose 150 ), $86.31 \%$ for batch $E$ (dose 50 ), 89.82\% for batch C (dose 50 ) and $90.40 \%$ for batch B (dose 130); and $82.98 \%$ when taking all four batches into consideration.

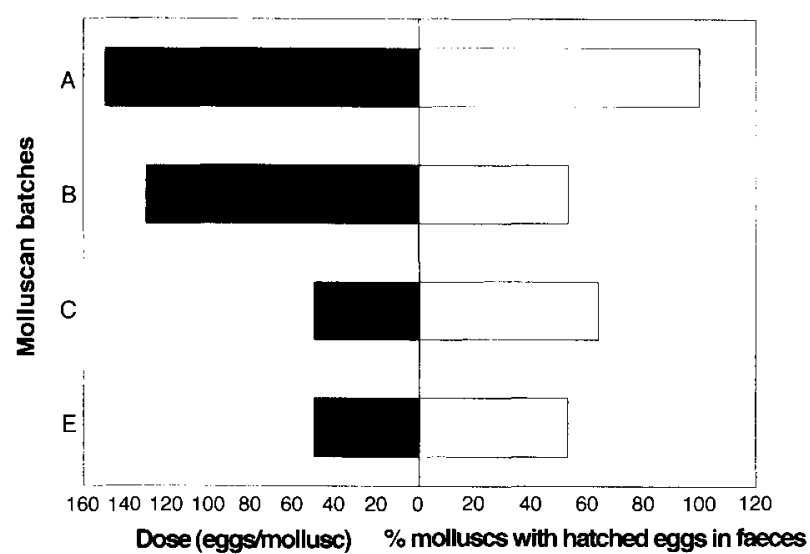

Fig. 4. Percentage of molluscs shedding Dicrocoelium dendriticum hatched eggs in faeces from each batch. Calculations based on the total number of molluscs tested with different doses.
The percentage of molluscs infected, calculated on the total of those examined from day 50 post-infection (p.i.) (the day on which the parasite was observed under the stereomicroscope for the first time) until the end of each experiment, varied between $17.53 \%$ (batch $B$ ) and $75 \%$ (batch A) (fig. 5). In the same way the percentage of molluscs in which an infection was detected, calculated on the total of those eliminating hatched eggs, ranged from $19.81 \%$ (dose 130 ) to $75 \%$ (dose 150 ), average 38.78 (fig. 5).

Despite examining molluscs up to day 217 p.i., we only observed infected ones until day 189 p.i. We established intervals of 20 days from day 50 p.i. (figs $6,7,9$ ) in order to summarize the results with reference to the percentages of molluscs in the following categories: infection; infection intensity and location; development stage of the parasites found. Although the highest percentage of infected molluscs was obtained between days 70 and 129 p.i., infected ones were observed between days 50 and 189 p.i.

On the other hand (fig. 7), molluscs with daughter sporocysts (hardly developed) concentrated at one or various points of the hepatopancreas (type A) were predominant until day 90 p.i. From then daughter sporocysts (containing germinal masses, an outline of cercariae or immature cercariae) began to migrate and invade larger areas of the hepatopancreas (type B) or all of it (type C) .

Of all the molluscs in which an infection was observed, the majority were infected with daughter sporocysts containing germinal masses of $D$. dendriticum $(67.9 \%)$. However, the highest percentage of molluscs with the parasite at this developmental stage $(23.24 \%)$ was recorded between days 70 and 90 p.i. Nevertheless, the percentage of molluscs containing sporocysts with developed, but not mature, cercariae (fig. 8) was low $(3.32 \%)$ and this stage of development was later observed on day 110 p.i. (fig. 9). On the other hand we did not observe any emission of slimeballs.

The chi-square test was used to detect statistically significant differences between batches A, B, C and E of tested C. (X.) cespitum arigonis, as far as the percentage of molluscs with hatched eggs is concerned $\left(\chi^{2}=24.66\right.$; $P \leq 0.005$; g.l. $=3$ ). Moreover, when the $2 \times 2$ contingency tables were applied, statistically significant differences for $P \leq 0.005$ between groups $A$ and $B ; A$ and $C$; $A$ and $E$; $E$ and $C$; and for $P \leq 0.05$ between groups $B$ and $C$ were detected.

\section{Discussion}

From our results, it seems sufficient to examine faeces eliminated by molluscs up to $48 \mathrm{~h}$ p.i. to check the hatching of $D$. dendriticum eggs, as our study did not detect any eggs after that period. Moreover, the greatest number of eggs was observed in faeces collected during the course of infection, which partly coincides with the work of Ratcliffe (1968), who found $20 \%$ of hatched eggs in the intestine of Helicella sp. 20 min after initial infection. In our experiments we did not observe a clear relationship between the dose used and the percentage of egg hatching in the molluscs, as the hatching value was higher in the batches given a dose of 50 eggs $(86.31 \%$, 
No.

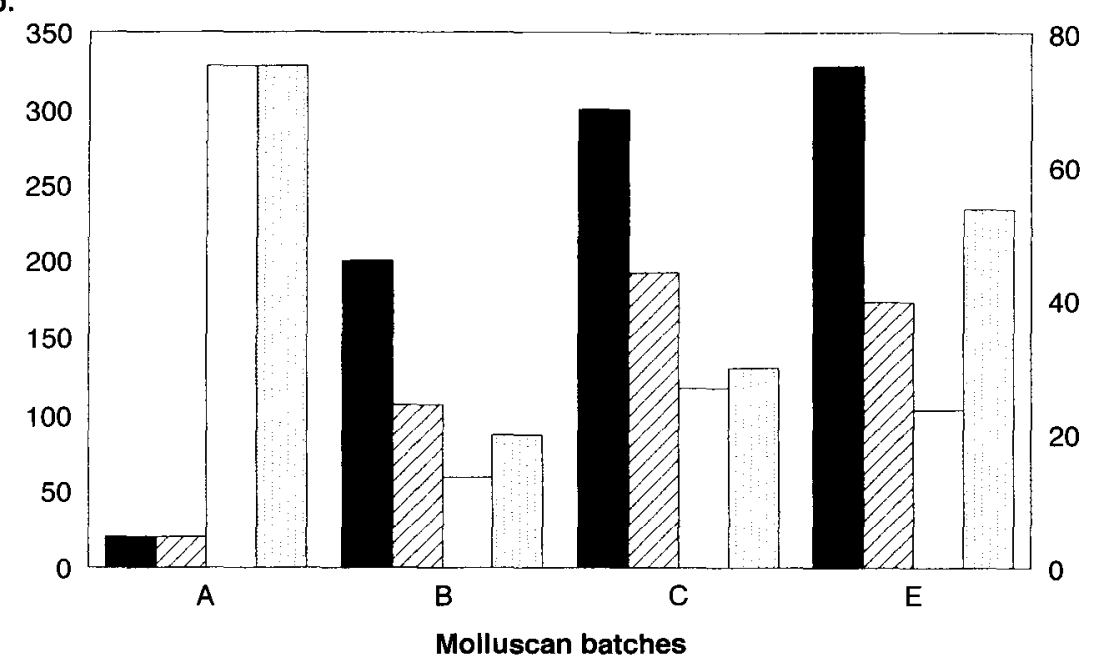

Fig. 5. Percentage of infected molluscs ( $\square$ ) calculated on the total number of molluscs examined

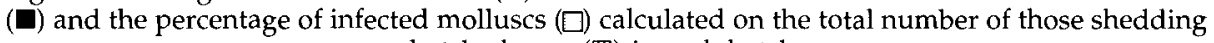
hatched eggs ( in each batch.

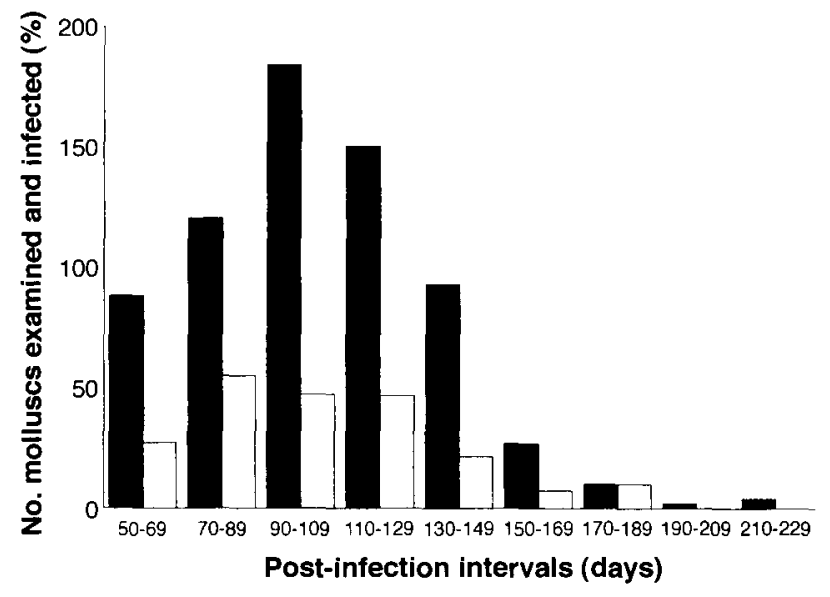

Fig. 6. Percentage of infected $(\square)$ molluscs, based on the total number of those examined ( $\square$ ) within each post-infection interval.

$89.82 \%)$ compared with those given 150 eggs $(65.42 \%)$. The same phenomenon was observed by Alunda \& RojoVázquez (1982) when five different batches of the same molluscan species were infected, as doses of 6.59 and 6.78 eggs produced higher hatching percentages $(80.68 \%$ and $81.81 \%$, respectively) than those with 9.5 eggs $(74.72 \%)$.

Similarly, no close relationship was detected between the percentage of molluscs containing hatched eggs in each batch and the dose used, as the percentage was lower in the batch infected with 130 eggs $(53 \%)$ compared with the one given 50 eggs (64\%). Similarly, Alunda \& Rojo-Vázquez (1982) obtained a lower hatching percentage when the dose was $9.25(96.29 \%)$ than with 6.78 and 8 $(97.96 \%$ and $100 \%)$, respectively.
The percentage of infected molluscs was generally lower than that in the batches of molluscs containing hatched eggs, except in those infected with 150 eggs, where both percentages were similar. The parasite was not visible under the stereomicroscope until 50 days $p . i$. under our study conditions, and it is possible that the real infection percentage could be somewhat higher. The fact that some molluscs, which eliminated hatched eggs with the faeces, were not found to be infected after killing coincides with that previously recorded by Mapes (1951), Tarry (1969) and Kalkan (1971).

The percentage of infected molluscs between days 50 and 69 p.i. $(27.27 \%)$ was lower than that obtained by Alunda \& Rojo-Vázquez (1982) between days 55 and 60 p.i. $(36.36-77.27 \%)$ in various batches of experimentally infected $C$. (X.) cespitum arigonis.

The first observation of $D$. dendriticum sporocysts on day 50 p.i. coincides with that recorded by Nöller (1932) in experimentally infected $Z$. detrita. This period is slightly shorter than that reported by Manga-González et al. (1995) in laboratory infected specimens of C. (X.) cespitum arigonis in the months of June and July and kept under controlled field conditions. However, it is longer than that detected by Mapes (1951) in Cionella lubrica (=Cochlicopa lubrica) ( 80 days p.i.) and by MangaGonzález et al. (1995) in experiments carried out during the cold months of the year (up to 9 months p.i.).

Our results show a diachronic development of the parasite in the mollusc, as, in spite of the infection occurring on the same day, each of the developmental stages were observed at different period p.i. Moreover, at times we also found second order sporocysts at different developmental stages in the same mollusc. Thus, sporocysts containing undifferentiated germinal masses and others harbouring developed cercariae were observed in molluscs examined between days 110 and 149 p.i. These results partially coincide with those of Timon-David 


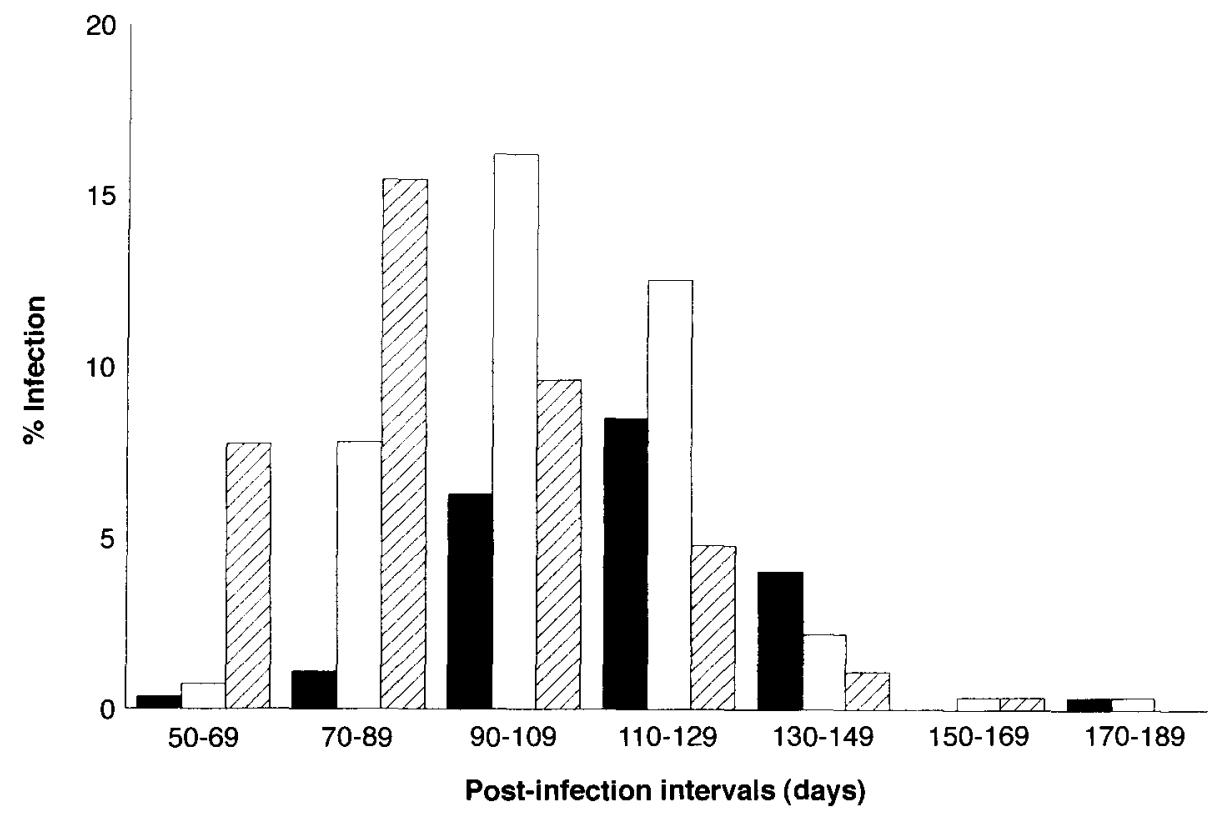

Fig. 7. Percentage of infected molluscs relative to the intensity and location of sporocysts in the hepatopancreas within each post-infection interval. A/ concentrated at one or various points ( B/ more widely-spread $(\square)$; C/ spread throughout the hepatopancreas ( $\square$ ).

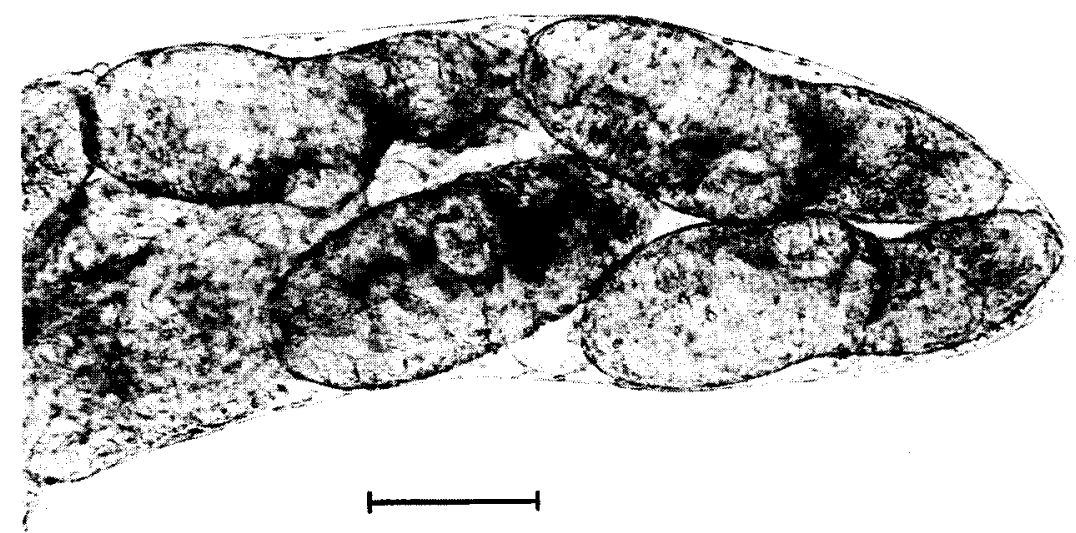

Fig. 8. Dicrocoelium dendriticum daughter sporocyst containing cercariae. Scale bar $=0.1 \mathrm{~mm}$.

(1965) who recorded sporocysts with germinal masses and young cercariae 123 days p.i. and cercariae with welldeveloped tails 186 days p.i. in Helicella (Helicopsis) arenosa. Badie \& Rondelaud (1990) found daughter sporocysts with cercariae between days 70 and 126 p.i. in Cochlicopa lubrica, while Chitiashvili et al. (1977) found them between 84 and 151 days p.i. in Helicella derbentina, Stenomphalia ravergieri, $H$. schelkovnicovi and $Z$. hohenackeri. In spite of having found infected molluscs up to day 189 p.i. we never did observe the emission of slimeballs, which would seem to indicate that the most developed cercariae found in our molluscs (110-149 days p.i.) were not yet mature and that parasite development requires longer under the conditions in which specimens of Cernuella (X.) cespitum arigonis were kept. Molluscan species and the conditions under which the infected hosts are maintained influence parasite development. Thus, in order to observe dicrocoeliid parasites in the molluscan host, the following periods of time are necessary: 150 to 165 days p.i. in Bradybaena fruticum (= Fruticicola 


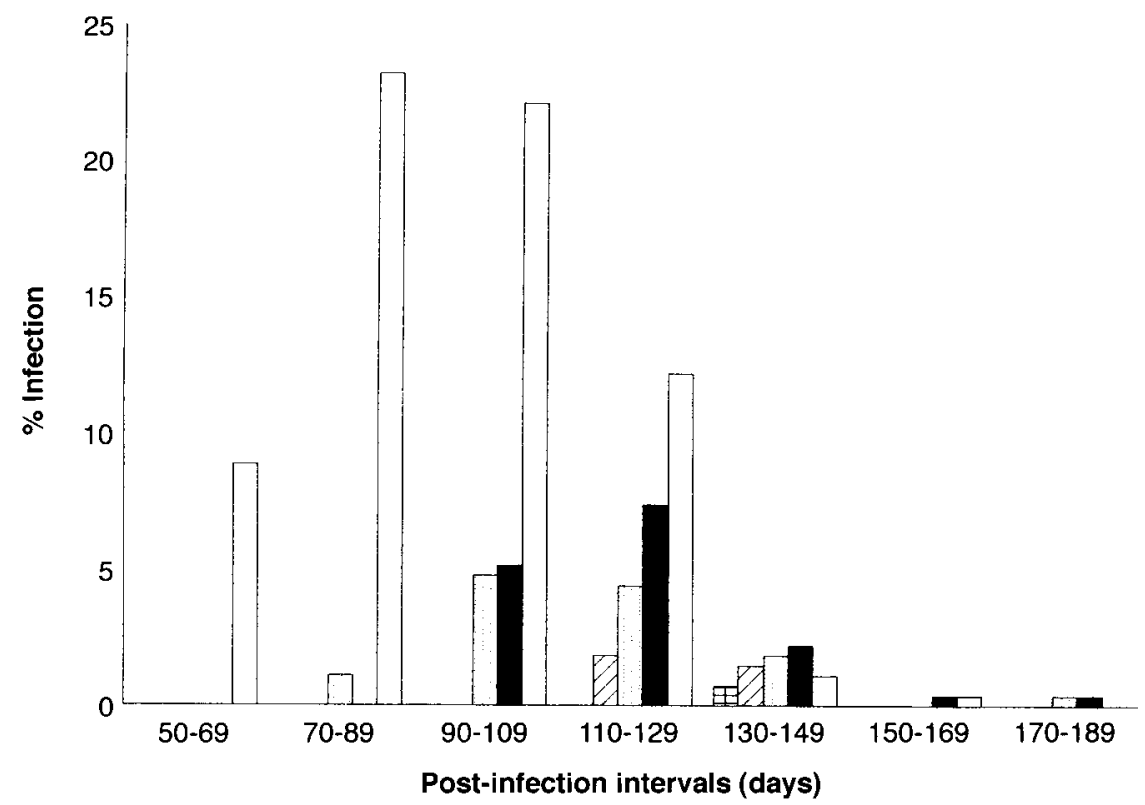

Fig. 9. Percentage of molluscs with Dicrocoelium dendriticum at different stages of development within each post-infection interval: $\square=$ sporocysts with undifferentiated germinal masses (sugm); $\mathbf{\square}=$ sporocysts with very immature cercariae (svic); ${ }^{2}=$ sporocysts with well developed, but not mature, cercariae (sdc); $\square=$ sugm + svic; $\boxplus=$ sugm + sdc.

fruticum), according to Vershinin (1957); 165 to 180 days p.i. in $H$. derbentina, $H$. crenimargo and $Z$. hohenackeri according to Grigoryan et al. (1956); and 186 days p.i. in H. (Helicopsis) arenosa according to Timon-David (1965). These periods of time contrast with 65 days p.i. in Z. hohenackeri, 70 days p.i. in B. fruticum and Euomphalia strigella and 85 days p.i. in Cochlicopa lubrica recorded by Tverdokhlebov (1973) in experiments carried out at $30^{\circ} \mathrm{C}$. On the other hand Krull \& Mapes (1952) stated that sporocysts do not produce cercariae in C. lubrica (=Cionella lubrica) until three or more months have passed.

\section{Acknowledgements}

We would like to thank M.L. Carcedo and C. Espiniella of the Estación Agrícola Experimental (CSIC) in León (Spain) for their technical assistance. This study was supported by the 'Junta de Castilla y León' (Project No. 0701/89) and CICYT (Project No. AGF92-0588).

\section{References}

Alunda, J.M. \& Rojo-Vazquez, F.A. (1982) Susceptibility of some populations of Cernuella (Xeromagna) cespitum arigonis (Schmidt, 1875) (Gastropoda, Helicidae) from the Douro Basin (Iberian Peninsula) to the infection by Dicrocoelium dendriticum (Trematoda). Malacología 22, 39-43.

Badie, A. \& Rondelaud, D. (1990) Dicrocoelium lanceolatum Rudolphi: Premieres donées sur la charge sporocystaire chez Cochlicopa lubrica Müller au cours d'une infestation experimentale. Bulletin de la Société Française de Parasitologie 8, 107-110.

Cabanas, E. (1995) Estudio del ciclo biológico de Dicrocoelium dendriticum (Rudolphi, 1819) Loos, 1899 en condiciones naturales. 362 pp. PhD Dissertation, Universidad de León, León, Spain.

Campo, R. (1996) Estudios experimentales sobre la dicroceliosis. 473 pp. PhDDissertation, Universidad de León, León, Spain.

Cordero-del-Campillo, M., Castañón-Ordóñez, I. \& RegueraFeo, A. (1994) Indice catálogo de zooparásitos Ibéricos. 650 pp. Universidad de León, León, Spain.

Chitiashvili, B.G., Chubabriya, I.T., Stepanov, A.V. \& Razmadze, E.D. (1977) [Development times of Dicrocoelium lanceolatum in larvae in the first and second intermediate host]. Sbornik Nauchnykh Trudov, Moskovskaya Veterinamaya Akademiya (Vazhneishie issledovaniya po izucheniyu zabolevanii Sel'skokhozyaistvennykh) 90, 78-80.

González-Lanza, C., Manga-González, M.Y. \& Del-PozoCarnero, P. (1993) Coprological study of the Dicrocoelium dendriticum (Digenea) egg elimination by cattle in higland areas in León Province, Northwest Spain. Parasitology Research 79, 488-491.

Grigoryan, G.A., Khanbergyan, R.A. \& Obanesyan, A.S. (1956) [The biology of Dicrocoelium lanceatum Stiles \& Hassall, 1896. (Preliminary report)]. Trudi Armyanskogo Nauchno-Issledovatelskogo Instituta Zhivotnovodstva $i$ Veterinarii, Veterinariya 9, 119-127.

Kalkan, A. (1971) Dicrocoelium dendriticum (Rudolphi, 1819) Looss, 1899 in Turkey. I. Field studies of intermediate and final hosts in the South Marmara region, 1968. British Veterinary Journal 127, 67-75. 
Krull, W.H. \& Mapes, C.R. (1952) Studies on the biology of Dicrocoelium dendriticum (Rudolphi, 1819) Looss, 1899 (Trematoda: Dicrocoeliidae), including its relation to the intermediate host, Cionella lubrica (Müller). VII. The second intermediate host of Dicrocoelium dendriticum. Cornell Veterinarian 42, 603-604.

Krull, W.H. \& Mapes, C.R. (1953) Studies on the biology of Dicrocoelium dendriticum (Rudolphi, 1819) Looss, 1899 (Trematoda: Dicrocoeliidae), including its relation to the intermediate host, Cionella lubrica (Müller). IX. Notes on the cyst, metacercaria, and infection in the ant, Formica fusca. Cornell Veterinarian 43, 389-410.

Lukin, A.K. (1980) [The prevalence and economic loss due to dicrocoeliasis in ruminants]. Trudy Saratovskoi NauchnoIssledovatel'skoi veterinamoi Stantsii 14, 76-79.

Malek, E.A. (1980) Snail-transmitted parasitic diseases. Volume II. 324 pp. CRC Press Inc.

Manga-González, M.Y. (1983) Los Helicidae (Gastropoda, Pulmonata) de la Provincia de León. 394 pp. Institución 'Fray Bernardino de Sahagún'. Excma. Diputación Provincial de León. Consejo Superior de Investigaciones Científicas (CECEL).

Manga-González, M.Y. (1987) Some aspects of the biology and helminthofaune of Helicella (Helicella) itala (Linnaeus, 1758) (Mollusca). Natural infection by Dicrocoeliidae (Trematoda). Revista Ibérica de Parasitología Vol. Extraordinario, 131-148.

Manga-González, M.Y. (1992) Some land molluscs species involved in the life cycle of Dicrocoelium dendriticum (Trematoda) in the wild in the province of León (NW Spain). pp. 248-249 in Giusti, F. \& Manganelli, G. (Eds) Abstracts of the 11th International Malacological Congress.

Manga-González, M.Y., González-Lanza, C. \& Del-PozoCarnero, P. (1991a) Dynamics of the elimination of Dicrocoelium dendriticum (Trematoda, Digenea) eggs in the faeces of lambs and ewes in the Porma basin (León, NW Spain). Annales de Parasitologie Humaine et Comparée 66, 57-61.

Manga-González, M.Y., González-Lanza, C., Espadaler, X. \& Otero-Merino, C. (1991b) Datos preliminares sobre la infestación por Dicrocoelium dendriticum de las hormigas $\left(2^{\circ}\right.$ hospedador intermediario) de la cuenca del Porma (León, España). pp. 256 in Mas-Coma, S., Esteban, J.G., Bargues, M.D., Valero, M.T. \& Galán-Puchades, M.T. (Eds) Parasitología en el Sur-Oeste de Europa. J. Aguilar, S.L. Valencia, Spain.

Manga-González, M.Y., González-Lanza, C., Del-PozoCarnero, P. \& Campo, R. (1995) Studies on experimental infection by Dicrocoelium dendriticum (Trematoda) of Cernuella (Xeromagna) cespitum arigonis (Mollusca) specimens in a natural environment. pp. 456-457 in Guerra, A., Rolán, E. \& Rocha, F. (Eds) Abstracts of Twelfth International Malacological Congress. Feito, S.L. Vigo, Spain.

Mapes, C.R. (1951) Studies on the biology of Dicrocoelium dendriticum (Rudolphi, 1819) Looss, 1899 (Trematoda: Dicrocoeliidae), including its relation to the intermediate host, Cionella lubrica (Müller). I. A study of Dicrocoelium dendriticum and Dicrocoelium infection. Cornell Veterinarian $41,382-432$.

Mattes, O. (1936) Der Entwicklungsgang des Lanzettegels Dicrocoelium lanceatum. Zeitschrift für Parasitenkunde 8, $371-430$.

Nöller, W. (1932) Über die Rolle der Wildkaninchen als Lanzettegelträger in einem Thüringer Lanzettegelbiete. Tierärztliche Umschau 38, 190-191.

Neuhaus, W. (1936) Untersuchungen über Bau und Entwicklung der Lanzettegel-Cercarie (Cercaria vitrina) und Klarstellung des Infektionsvorganges beim Endwirt. Zeitschrift für Parasitenkunde 8, 431-473.

Ractliffe, L.H. (1968) Hatching of Dicrocoelium lanceolatum eggs. Experimental Parasitology 23, 67-78.

Rosicky, B. \& Groschaft, J. (1982) Dicrocoeliosis. pp. 33-52 in Hillyer, G.V. \& Hopla, C.E. (Eds) CRC handbook series in zoonoses. Section C: parasitic zoonoses. Volume III. Boca Raton, Florida, USA, CRC press, Ind.

Tarry, D.W. (1969) Dicrocoelium dendriticum: the life cycle in Britain. Journal of Helminthology 43, 403-416.

Timon-David, J. (1965) Infestation expérimentale d'une hélicelle par huit espèces de trématodes digénétiques appartenant à quatre familles différentes. Annales de Parasitologie Humaine et Comparée 40, 149-154.

Tverdoklebov, P.T. (1973) [Biological basis for the forecasting of Dicrocoelium infections]. Trudy Vsesoyuznogo Instituta Gel' mintologii im K.I. Skryabina 20, 185-191.

Vershinin, I.I. (1957) [Epizootiology of Dicrocoelium infections of sheep and its biology in the Kaluga region]. Trudy Moskovskoy Veterinarnoi Akademii 19, 3-15.

Wolff, K., Hauser, B. \& Wild, P. (1984) Dicrocoeliose des Schafes: Untersuchungen zur Pathogenese und zur Regeneration des Leber nach Therapie. Berliner und Münchener Tierärztliche Wochenschrift 97, 378-387.

(Accepted 4 June 1997)

(C) CAB INTERNATIONAL, 1997 